\title{
Diversification in a biodiversity hotspot - The evolution of Southeast Asian rhacophorid tree frogs on Borneo (Amphibia: Anura: Rhacophoridae)
}

\author{
Stefan T. Hertwig ${ }^{\mathrm{a}, *}$, Manuel Schweizer ${ }^{\mathrm{a}}$, Indraneil Das ${ }^{\mathrm{b}}$, Alexander Haas ${ }^{\mathrm{c}}$ \\ ${ }^{a}$ Naturhistorisches Museum der Burgergemeinde Bern, Bernastrasse 15, CH-3005 Bern, Switzerland \\ ${ }^{\mathrm{b}}$ Institute of Biodiversity and Environmental Conservation, Universiti Malaysia Sarawak, 94300 Kota Samarahan, Sarawak, Malaysia \\ c Biozentrum Grindel und Zoologisches Museum Hamburg, Martin-Luther-King-Platz 3, 20146 Hamburg, Germany
}

\section{A R T I C L E I N F O}

\section{Article history:}

Received 26 October 2012

Revised 28 March 2013

Accepted 1 April 2013

Available online 8 April 2013

\section{Keywords:}

Amphibia

Anura

Rhacophoridae

Southeast Asia

Phylogeny

Taxonomy

Evolution of reproductive modes

\begin{abstract}
A B S T R A C T
The tree-frog family Rhacophoridae is a major group contributing to the high pecies richness and reproductive diversity among vertebrates of Sundaland. Nonetheless, rhacophorid evolution, specially on Borneo, has not been studied within a phylogenetic context. In this study, we examine the phylogenetic relationships of 38 (out of 41) Bornean species of Rhacophoridae, in combination with data from previous phylogenetic studies. In the final super matrix of 91 species, we analyse sequence data from two mitochondrial and three nuclear genes. The resulting trees show the genus Rhacophorus as a paraphyletic assemblage. As a consequence, we transfer Rhacophorus appendiculatus and $R$. kajau to two other genera and propose the new phylogeny-based combinations- Kurixalus appendiculatus and Feihyla kajau, respectively. Furthermore, we use our phylogenetic hypotheses to reconstruct the evolution of reproductive modes in rhacophorid tree frogs. Direct development to the exclusion of a free larval stage evolved twice independently, once in an ancestor of the Pseudophilautus + Raorchestes clade in India and Sri Lanka, and once within Philautus in Southeast Asia. The deposition of egg clutches covered by a layer of jelly in Feihyla is also present in F. kajau and thus confirms our generic reassignment. The remarkably high diversity of rhacophorid tree frogs on Borneo is the outcome of a complex pattern of repeated vicariance and dispersal events caused by past changes in the climatic and geological history of the Sunda shelf. We identified geographic clades of closely related endemic species within Rhacophorus and Philautus, which result from local island radiations on Borneo.
\end{abstract}

(c) 2013 Elsevier Inc. All rights reserved.

\section{Introduction}

The biogeographic region termed Sundaland, which consists of the Malay Peninsula, Borneo, Sumatra, Java, Bali, Palawan and some smaller islands, is a global biodiversity hotspot (Myers et al., 2000). The extraordinarily high species richness found in numerous groups of plants and animals in this region is probably the result of its complex geological and climatological history (Den Tex et al., 2010; Esselstyn et al., 2010; Hall, 1998, 2002; Heaney, 1986). The rhacophorid frogs in this area are a prime example of a highly diverse vertebrate group. Similar to India and Sri Lanka (Meegaskumbura et al., 2002), Southeast Asia and Sundaland, in particular, constitute one of the centres of high species richness of the taxon Rhacophoridae (Liem, 1970; Channing, 1989; Frost et al., 2006; Pyron and Wiens, 2011). The approximately 300 extant species exhibit a broad variety of ecological adaptations and micro-

\footnotetext{
* Corresponding author.

E-mail addresses: stefan.hertwig@nmbe.ch (S.T. Hertwig), manuel.schweizer@nmbe.ch (M. Schweizer), idas@ibec.unimas.my (I. Das), alexander.haas@unihamburg.de (A. Haas).
}

habitat preferences, mirrored by impressive variation in body size, colouration and other aspects of external morphology. This diversity also extends to modes of reproduction, which are typically associated with habitat preferences and range from the production of foam nests for egg protection to direct development without free-swimming larval stages (Brown and Alcala, 1983, 1994; Channing, 1989; Grosjean et al., 2008; Li et al., 2009, 2011; Liem, 1970). Our knowledge and understanding of the evolution of these diverse reproductive strategies in rhacophorid tree frogs, however, are relatively sketchy; our observations of their field ecology are anecdotal.

Within Rhacophoridae, the taxon Buergeriinae Channing, 1989 consists of only one genus of four described species (Frost, 2011). In contrast, the taxon Rhacophorinae Hoffmann, 1932, which constitutes the other major group, comprises about 300 described species. Although numerous studies have been published on the phylogenetic relationships and resulting systematics of Rhacophorinae, the phylogeny of many of its genera and species remains a matter of debate (Biju et al., 2008; Channing, 1989; Delorme et al., 2005; Frost et al., 2006; Grosjean et al., 2008; Hertwig et al., 2012; Li et al., 2008, 2009; Liem, 1970; Pyron and Wiens, 